
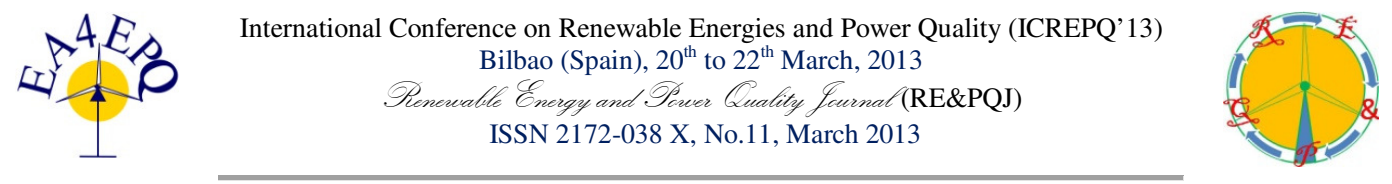

\title{
Short Time Voltage Variations Analysis for the new Brazilian Distribution Procedures (PRODIST) and for the IEC 61000-4-30
}

\author{
G. S. Wojichowski ${ }^{1}$, C. D. P. Crovato ${ }^{2}$ and R. C. Leborgne ${ }^{1}$ \\ ${ }^{1}$ Department of Electrical Engineering \\ Universidade Federal do Rio Grande do Sul \\ Av. Osvaldo Aranha 103, Porto Alegre - Rio Grande do Sul (Brazil) - CEP 90035-190 \\ Phone number: +5551 99681929, e-mail: guilherme.wojichowski@ufrgs.br , rcl@ece.ufrgs.br \\ ${ }^{2}$ Feevale University \\ ERS239, 2755, Novo Hamburgo - CEP: 93352-000 - Rio Grande do Sul (Brazil) \\ Phone number: +5551 33584016, e-mail: cesarc@feevale.br
}

\begin{abstract}
This paper presents the analysis of one important requirement of the new Brazilian regulation of Power Quality. The Electric Distribution Procedures (PRODIST), that includes power quality regulation, stipulates the references and methods of measurements to the Electrical Utilities that soon will become a standard that will have limits that must be achieved. The main target of this paper is to compare and propose a specific calculus methodology for a Power Quality Analyzer to precisely identify the amplitude and duration of Short Time Voltage Variations requested in the PRODIST. The PQ Analyzer complies PRODIST technical specifications and the International Standard IEC61000-4-30 for some aspects that PRODIST is not clear. The weak points that are not specified in the PRODIST are also analyzed, showing that they should be more precise, otherwise if different manufactures choose distinct methods, procedures and algorithms, they will not reach the same results. Therefore, power quality measurements could not be compared using equipment of different manufacturers.
\end{abstract}

\section{Key words}

Power Quality Analyzer, Brazilian Power Quality Standard (Prodist), Short Time Voltage Variation

\section{Introduction}

The Power Quality (PQ) issues in Brazil are regulated by the Electrical Energy Regulation Agency (ANEEL). The Brazilian Electric Distribution Procedures (PRODIST) [1] is composed of eight modules, the one concerned about the PQ is Module 8, that states the parameters that should be measured such as: steady state voltage magnitude, power factor, voltage harmonics, voltage unbalance, voltage fluctuation (flicker), voltage variation and frequency variation. The problem is that PRODIST does not mention the calculus method for detection of short time voltage variation (STVV). The IEC 61000-4-30 [2] states a specific method to measure the STVV. The main objective of this paper is to present, analyse and compare several methods to measure STVV. The method that presents the best performance is proposed to be used by both standards, and by the manufactures of Power Quality Analyzers.

\section{PRODIST and IEC 61000-4-30 Short Time Voltage Variations Analysis}

The PRODIST shows how to measure and characterize the disturbances and the reference values to the power quality compliance. The minimum hardware requirements for the measurement system according to the regulation are: Digital sampling of 16 samples per cycle; Analog to Digital converter of 12 bits; Precision: $1 \%$ of the reading value.

The PQ disturbances according to PRODIST are:

Steady State Voltage Magnitude; Power Factor; Voltage Harmonics; Voltage Unbalance; Flicker; Short Time Voltage Variations; and Frequency variation.

Only the Short Time Voltage Variation will be analysed in this paper. The Short Time Voltage Variations are determined by the RMS voltage and the duration of the disturbances is between half cycle and 3 minutes [2]. They are classified by PRODIST in six types showed in Table I.

\section{Analysis and Proposal of Calculus Methodology}

The methods described below show different ways of detecting and calculating the magnitude and duration of short time voltage variations. 


\section{A. Method 1: RMS Value measured over a cycle refreshed each new cycle}

Figure 1 shows 2 steps to exemplify this method. This algorithm takes a completely new window of one cycle of data to calculate rms voltage.
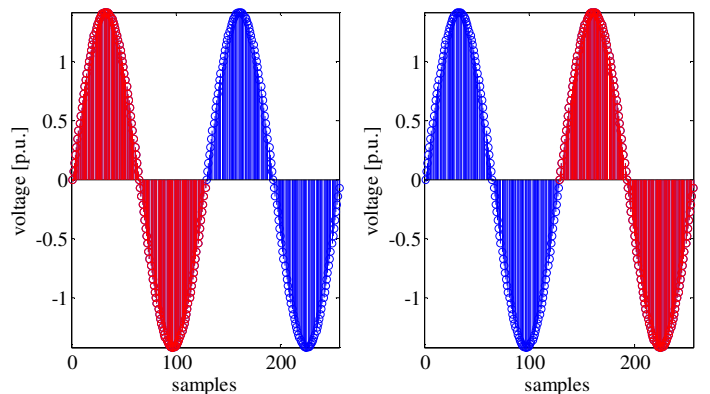

Fig. 1. Method 1: one cycle window updated each cycle

Table I. - Short Duration Voltage Variations according to PRODIST

\begin{tabular}{|l|c|c|}
\hline \multicolumn{1}{|c|}{ Type } & Duration & Voltage Magnitude \\
\hline $\begin{array}{l}\text { Momentary Voltage } \\
\text { Interruption }\end{array}$ & $<=3 \mathrm{~min}$ & $<0,1$ p.u. \\
\hline $\begin{array}{l}\text { Momentary Voltage } \\
\text { Sag }\end{array}$ & $\begin{array}{c}>=\text { one cycle } \\
\text { and }<=3 \\
\text { seconds }\end{array}$ & $\begin{array}{c}>0,1 \text { p.u. and }<0,9 \\
\text { p.u. }\end{array}$ \\
\hline $\begin{array}{l}\text { Momentary Voltage } \\
\text { Swell }\end{array}$ & $\begin{array}{c}>\text { one cycle and } \\
<3 \text { seconds }\end{array}$ & $>1,1$ p.u. \\
\hline $\begin{array}{l}\text { Temporary Voltage } \\
\text { Interruption }\end{array}$ & $\begin{array}{c}>=3 \text { seconds } \\
\text { and }<3 \text { minutes }\end{array}$ & $<0,1$ p.u. \\
\hline $\begin{array}{l}\text { Temporary Voltage } \\
\text { Sag }\end{array}$ & $\begin{array}{c}>=3 \text { seconds } \\
\text { and }<3 \text { minutes }\end{array}$ & $\begin{array}{c}>0,1 \text { p.u. and }<0,9 \\
\text { p.u. }\end{array}$ \\
\hline $\begin{array}{l}\text { Temporary Voltage } \\
\text { Swell }\end{array}$ & $\begin{array}{c}>=3 \text { seconds } \\
\text { and }<3 \text { minutes }\end{array}$ & $>1,1$ p.u \\
\hline
\end{tabular}

B. Method 2: RMS Value measured over a cycle refreshed each new half cycle

Figure 2 shows 2 steps to exemplify this method. This algorithm takes a window of one cycle of data to calculate rms voltage performing the calculation each half cycle.
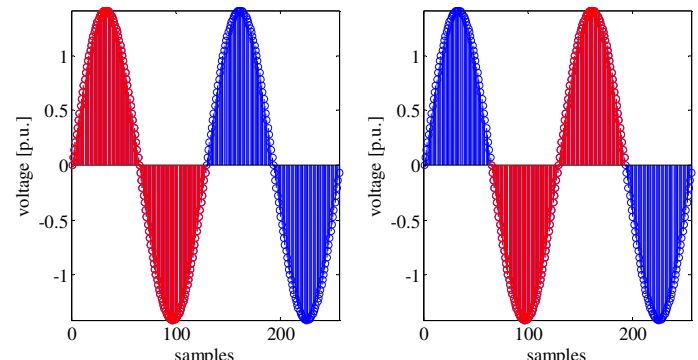

Fig. 2. Method 2: one cycle window updated each half cycle

\section{Method 3: RMS Value measured over a cycle refreshed} each new sample

Figure 3 shows 2 steps to exemplify this method. This algorithm takes a window of one cycle of data to calculate rms voltage performing the calculation each time a new sampled is obtained.
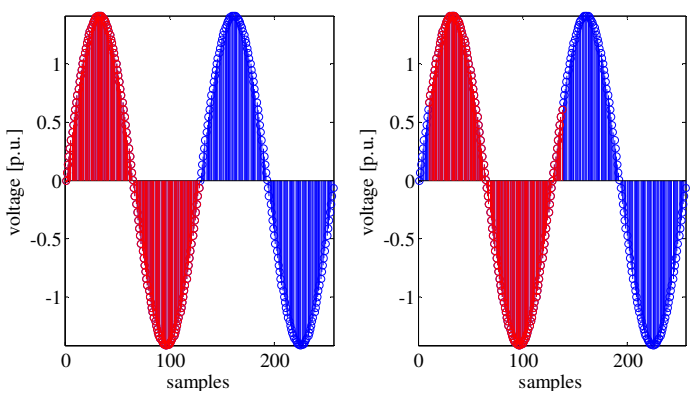

Fig. 3. Method 3: one cycle window updated for each sample

D. Method 4: RMS Value measured over half cycle refreshed each new half cycle

Figure 4 shows 2 steps to exemplify this method. This algorithm takes a window of half cycle of data to calculate rms voltage performing the calculation each half cycle.
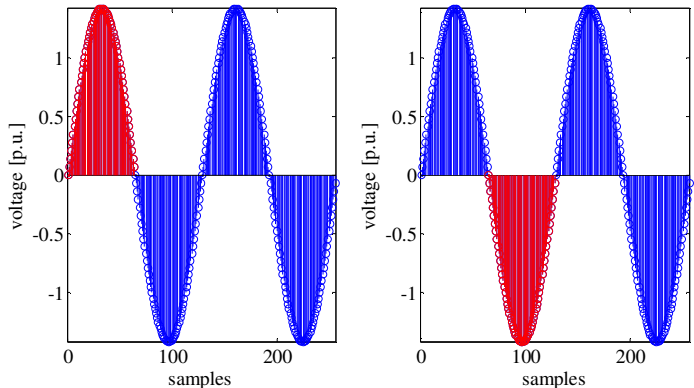

Fig. 4. Method 4: half cycle window updated each half cycle

E. Method 5: RMS Value measured over half cycle refreshed each new sample

Figure 5 shows 2 steps to exemplify this method. This algorithm takes a window of half cycle of data to calculate rms voltage performing the calculation each time a new sampled is obtained.
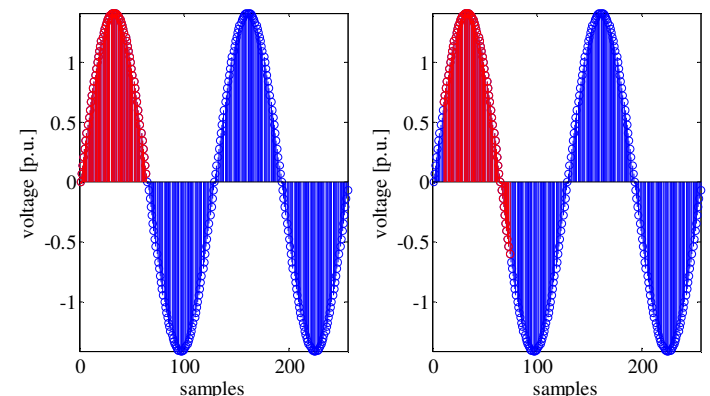

Fig. 5. Method 5: half cycle window updated for each new sample 


\section{Case Study}

Figure 6 shows the comparison of the 5 methods applied in a simulation of a short time voltage variation of 0.2 p.u. and duration of half cycle. Method 1 is blue, method 2 is pink, method 3 is black, method 4 is red and method 5 is green.
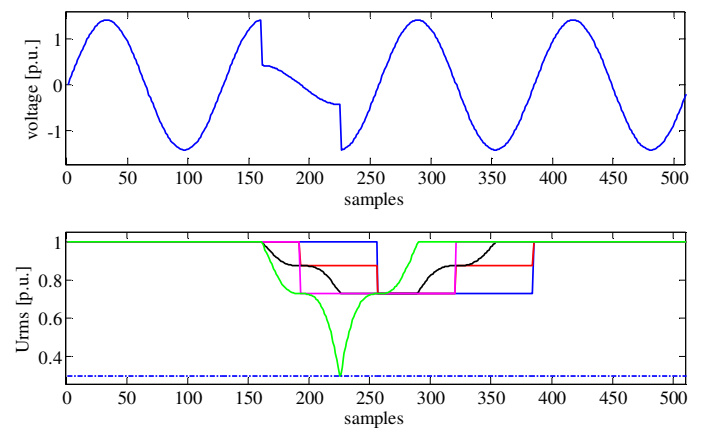

Fig. 6. First Methods Comparison

It is clear that the only method that could measure this disturbance accurately is the method RMS Value measured over a half cycle refreshed each new sample, the green line.

Figure 7 shows the comparison of the 5 methods applied in a simulation of a short time voltage variation of 0.2 p.u. and duration of one cycle and a half. Method 1 is blue, method 2 is pink, method 3 is black, method 4 is red and method 5 is green. It is possible to see in this case that all the methods were capable of detecting the voltage variation and correctly measure the amplitude, but the time duration was not correctly measure by all the methods.
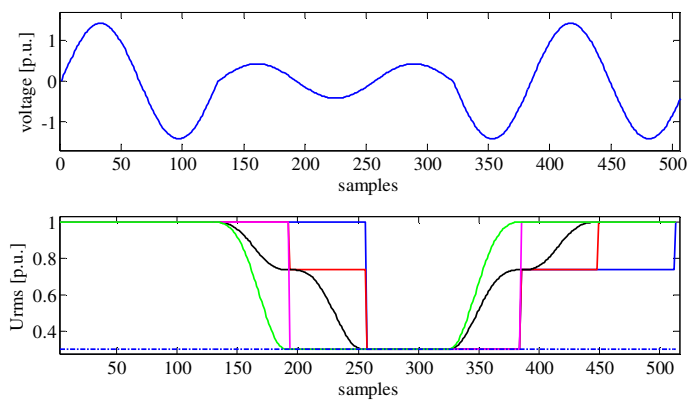

Fig. 7. Second Methods Comparison

Only 2 methods were capable of measuring the duration of the short time voltage variation, the RMS Value measured over a half cycle refreshed each new sample, the green line and the RMS Value measured over a half cycle refreshed each new half cycle, the pink line.

It is important to notice that depending of the duration and the moment that the variation starts, different methods could detect equal values of time duration and equal voltage magnitude, for example, if the variation has exactly the duration a cycle, and this cycle is synchronized with the voltage source, all the methods would detect and measure the same results as showed in figure 8 .
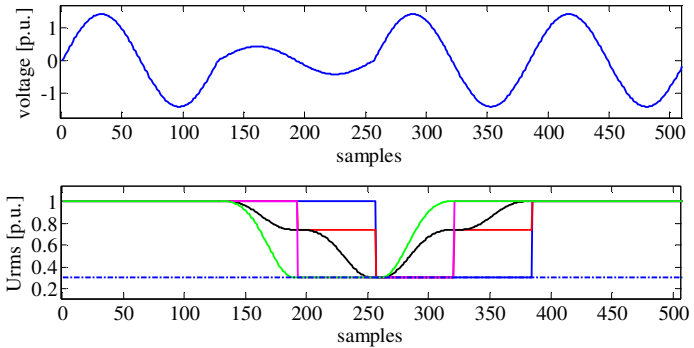

Fig. 8. Third Methods Comparison

Figure 8 also shows that if this was the only test and simulation it would be possible to agree that PQ Analysers with different detection methods could correctly measure the amplitude and duration of a short time voltage variation.

After the simulation showed before, two methods were used in two different PQ Analysers prototypes measuring the same industry grid. The methods used were: $R M S$ Value measured over a cycle refreshed each new half cycle; and RMS Value measured over half cycle refreshed each new sample.

The reason why these methods were chosen is because the first one is stated by the IEC $61000-4-30$ as the one that should be followed, and the second had the best results in the simulation. The Table 2 shows the comparison of one week of measurement and shows the differences between the methods.

\begin{tabular}{|l|c|c|}
\hline \multicolumn{1}{|c|}{ Method } & $\begin{array}{c}\text { Quantity } \\
\text { Detected }\end{array}$ & Type \\
\hline $\begin{array}{l}\text { One cycle window } \\
\text { refreshed each new } \\
\text { half cycle }\end{array}$ & 15 & $\begin{array}{l}\text { Momentary } \\
\text { Voltage } \\
\text { Interruption }\end{array}$ \\
\hline $\begin{array}{l}\text { Half cycle window } \\
\text { refreshed each new } \\
\text { sample }\end{array}$ & 90 & $\begin{array}{l}\text { Momentary } \\
\text { Voltage } \\
\text { Interruption }\end{array}$ \\
\hline
\end{tabular}

Table II. - Comparison between 2 methods

After analyzing the results of Table II, different from what is said in [5], it is possible to say that there is a large difference in the quantity of disturbances detected depending of the method that the Power Quality Analyzer uses in the RMS calculation. It is important to say that the detection is based on the rms voltage reaching the limits stated in Table 1, and not by the duration of the event, the duration is only measured if an event is first detected. So, another future case study would be to analyse the time duration of different methods, so that maybe Momentary Voltage Interruptions could wrongly be classified as Temporary Voltage Interruptions as discussed in Figure 7. 


\section{Conclusion}

The main methods of short time voltage variations detections have been discussed. A proposal of a unique method that complies PRODIST and IEC 61000-4-30 standard was introduced. With this proposal it will be possible that Power Quality Analyzers manufactures start to use the same methodology for detecting this kind of disturbance. As showed in the case study if different manufactures use distinct methods and procedures to detect the short time voltage variations, the results will not converge so that the analysis of the power quality disturbances will not be accurate.

\section{Acknowledgement}

This work was supported by Embrasul Electronic Industry Ltda www.embrasul.com.br and Feevale University www.feevale.br

\section{References}

[1] ANEEL - Procedimentos de Distribuição de Energia Elétrica no Sistema Elétrico Nacional - PRODIST - Módulo 8 Qualidade da Energia Elétrica - Brazil

[2] IEC 61000-4-30 - International Standard - Electromagnetic compatibility (EMC) - Part 4-30: Power Quality Measurement Methods

[3] E. P. Fernández - Nuevo Método de Detección y Análisis en Tiempo Real de Eventos en la Tensión de Suministro de Energía Eléctrica Empleando un Modelo Combinado - Tesis Doctoral Universidade de Cantabria

[4] C. D. P. Crovato, A. A. Susin - Implementação da IEC 61000-4-30 Classe A em sistemas embarcados - Sicel - Rio de Janeiro

[5] T. N. Ribeiro, D.M. Correia, D.O.C. Brasil - NOS and Agents Effort to Face Short Voltage Variations in Brazil 